\title{
EDUCAÇÃO DE ADULTOS MIGRANTES
}

\section{A experiência de um professor nativo}

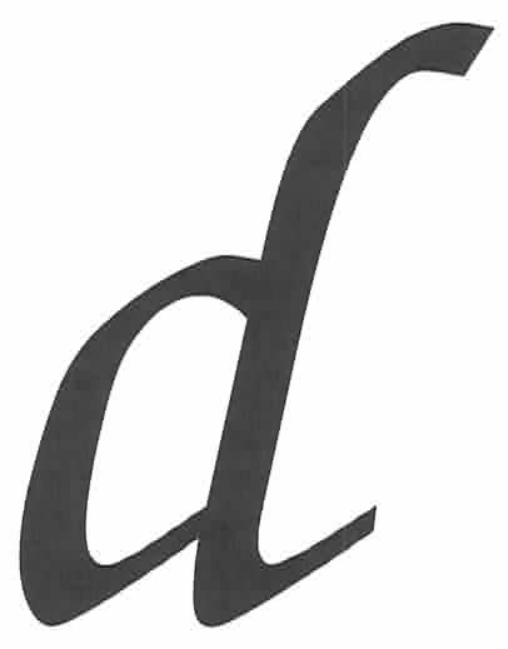

iferente do que acontece com inúmeros estudiosos dedicados ao tema das migrações, não sou eu mesmo um migrante. Ainda que o assunto fale mais alto pela biografia de meus antepassados, minha história pessoal aderiu ao solo natal: sempre vivi em São Paulo. Ainda assim, é a partir de uma experiência imediata que os deslocamentos dos homens, especialmente nos limites internos do território nacional, mobilizam meu interesse como psicólogo social. Se o fenômeno me é instigante, isso se deve ao contato duradouro que venho mantendo com grupos de migrantes radicados nesta cidade.

Há quase uma década, participo como educador de jovens e adultos em um curso noturno subsidiado pelo Colégio Santa Cruz, escola particular localizada na zona oeste da cidade, que durante $o$ dia abre suas portas a crianças e adolescentes. Esse curso supletivo, no qual dou aulas de Ciências, atende de quatro a cinco centenas de homens e mulheres com idade mínima de dezesseis anos, distribuídos em classes que vão da alfabetização ao Ensino Médio. Do total de alunos matriculados no início de $2006,68 \%$ eram oriundos de estados do Nordeste $(45 \%$ eram da Bahia), 10\% de Minas Gerais, além de outros que, em menor quantidade, vieram do Rio de Janeiro e de estados das regiões Sul e Centro-Oeste do país. Trata-se, portanto, de uma escola que atende um número significativo de migrantes.

A trajetória escolar de grande parte dos alunos desse curso participa de uma história de deslocamentos. Em sua maioria, viveram o período antecedente à migração em áreas rurais, lugarejos onde a frequiência à escola não tomava parte na tradição e tampouco se fazia premente. Aqueles que chegaram a ingressar na vida escolar tiveram uma experiência efêmera, em muitos casos interrompida pela migração.

$\mathrm{O}$ perfil desses migrantes com quem convivo quase diariamente é aquele de milhares de homens e mulheres que, a par da crescente 
migração de retorno para o Nordeste brasileiro, adensam as levas que ainda fazem de São Paulo o principal destino de nordestinos com baixa escolaridade (Rigotti, 2006).

$\mathrm{Na}$ chegada à metrópole, as questões relativas à moradia e ao trabalho mobilizam todos os esforços. Entre os alunos do curso em foco, a maioria foi absorvida como mão-deobra em serviços domésticos ou no comércio, $60 \%$ deles remunerados em até dois salários mínimos, $80 \%$ recebendo até três salários mínimos mensais. Muitos moram no local de trabalho. As mais urgentes exigências da vida na cidade, somadas aos percalços da adaptação a este universo, costumam impedir uma conciliação com os estudos. E relegam a escolarização a um campo de necessidades que, se existentes, deverão aguardar para, quiçá um dia, serem satisfeitas. A quase totalidade dos migrantes com quem venho tendo contato acabou por ingressar à escola quando alguns anos haviam transcorrido desde sua chegada a São Paulo.

Ainda hoje, como há tempos apontava Eunice Durhan (1973), é comum que o migrante disponha do apoio de parentes ou conhecidos que vieram primeiro e com quem compõe uma rede social no lugar de destino. Tenho verificado, em contrapartida, a importância da escola como espaço de socialização desses alunos na cidade. Em meio a um cotidiano em que costumam ocupar posições subordinadas, geradoras de isolamento, a escola noturna acaba por constituir um território de relações igualitárias com outros indivíduos, freqüentemente familiares e conterrâneos, cujas trajetórias se assemelham às suas. Há pequenos municípios brasileiros, como São João do Paraíso
(MG), Belo Campo (BA) e Tremedal (BA) que, entra ano sai ano, contam com dezenas de alunos nessa escola. Se a migração estabeleceu-se como tradição em sua comunidade original, o ingresso na escola se assemelha a uma tradição secundária. O encontro diário mantém o grupo coeso e realça o caráter coletivo da resistência frente aos sofrimentos gerados pela dispersão. Os encontros com outros migrantes como que favorecem o ingresso em um campo intersubjetivo em que os indivíduos experimentam ser reconhecidos. Sua aparição diante de um outro que é igualmente um migrante pertencente às classes pobres, junto a quem experimenta uma comunidade de destino, atribui um sentido à própria existência.

Se consiste em um espaço de encontro entre iguais, a escola também aproxima o migrante de pessoas cujas formações muito divergem da sua.

\section{MIGRAÇÕES E CULTURAS BRASILEIRAS}

As migrações internas realizadas por esses homens e mulheres agora estudantes não podem ser pensadas como deslocamentos intrínsecos a um meio cultural uniforme. Inversamente, representam trânsitos entre quadros de expressões materiais e espirituais distintas e que Alfredo Bosi (2000), enfatizando seu caráter plural, chamou de culturas brasileiras. Sua heterogeneidade assenta sobre as divisões de uma sociedade de classes.

No ambiente sertanejo em que viveu a maior parte de meus alunos, prevalece o que se costuma chamar de cultura popular. Ainda que não haja uma unidade entre suas definições por diferentes estudiosos, pode-se dizer que a cultura popular envolve um rol de manifestações do povo que passam ao largo dos esquemas oficiais. Seus usos e costumes, freqüentemente nomeados como folclore, compõem um jeito de viver que se desenrola sob o limiar da escrita. A coesão grupal é cimentada pela oralidade sobre a qual se assentam as tradições.

Em contraste, a cidade é um espaço marcado pela sociedade letrada, regido pela escrita e por códigos ratificados por instituições que vivem no âmbito da cultura erudita. Os saberes que transitam nessa esfera da ciência dominante são produzidos em instâncias sociais muito distantes do homem do povo e de seus interesses como classe social. Entretanto, a própria sobrevivência na metrópole aos poucos parece exigir alguma modalidade de incorporação desses elementos a seu repertório.

Nas noites em que nos encontramos, os alunos vêm de exaustivas jornadas de trabalho. Soma-se a isso o ônus de longos e tumultuados deslocamentos pela cidade, as árduas negociações com patrões nem sempre dispostos a abrir mão de um empregado que insiste em estudar, a ameaça das ruas à circulação noturna e as parcas horas restantes ao descanso. Quando nos despedimos, não tardará para que tudo recomece. Dores de cabeça, dores musculares, tremores, vista cansada, indisposições estomacais, pressão alta, pressão baixa, fome e sono: não são poucos os sintomas gerados por um cotidiano assim desenhado. Todos esses esforços tornam notórios o interesse e o compromisso dos alunos para com as aulas, a tarefa de aprender, enfim, a escola. E despertam indagações a respeito de sua natureza.

Ao longo dos anos, algumas hipóteses sobre a relevância da 
aprendizagem formal para esses adultos foram se desenhando em meu campo de reflexões, nenhuma delas dando conta do fenômeno como um todo ou sendo excludente das demais. Para alguns alunos, a escolarização tardia representa a realização de um desejo mantido em compasso de espera por toda uma vida. Pode também ser vivida como a mais vigorosa aproximação de códigos disseminados pelas instituições dominantes na cidade e que colaboram para convertê-la em um mundo enigmático. Consideremos ainda a escolarização como suposta busca de prestígio pessoal. E, finalmente, como suposto requisito para ascender no mercado de trabalho.

Em uma sociedade industrial, é poderosa a influência da cultura de massas. Ainda assim, nosso esforço aqui repousa sobre o encontro entre a cultura popular e a cultura erudita. Não como categorias estanques do fazer e do pensar, mas como manifestações que se relacionam mediante múltiplas interfaces. Uma escola que abre suas portas a adultos, muitos deles migrantes, oferece uma abertura a essa comunicação. Pois a instituição, mediante a figura dos educadores, tem a incumbência de estender o conhecimento produzido pela intelectualidade dominante a homens e mulheres que trazem consigo o que se costuma chamar de sabedoria popular.

Seja como reinterpretação, refacção ou decodificação, a apropriação de um certo conhecimento erudito pelo homem iletrado tem sido, historicamente, um tema recorrente entre os estudiosos da cultura popular. Em sentido inverso, o que aqui me proponho a pensar é o modo pelo qual a cultura popular pode repercurtir sobre um homem formado em meios letrados. Para alguém cuja vida é sedentária, a convivência prolongada com migrantes pode proporcionar novas perspectivas sobre formas de conhecimento e sobre a cidade em que sempre viveu.

\section{O OUTRO E A EXPERIÊNCIA DE ESTRANHAR}

Gostaria de propor três aspectos relativos à experiência como professor como eixos de reflexão.

1. Um adulto que retoma um processo de escolarização é alguém que herdou saberes e princípios transmitidos por instâncias sociais outras que não a escola. Quando chega a ela, já traz consigo algum repertório de experiências de vida. No caso de muitos dos alunos com quem tenho contato, essa formação primordial ficou a cargo de grupos familiares e das relações de trabalho rural.

Em um curso destinado a jovens e adultos, são recorrentes as situações promotoras de encontros (e desencontros) entre conhecimentos produzidos pela ciência dominante e aquele conjunto de saberes que ela nomeia senso comum. O professor, munido de uma racionalidade denominada lógico-científica, acaba por penetrar os meandros de formas de pensamento que operam por meio de uma outra racionalidade, marcadamente empírica, pouco afeita a abstrações e dotada de critérios próprios de validação do conhecimento. Aproxima-se de uma visão de mundo divergente daquela que é ensinada pelas instituições escolares.

2. Muitas são as situações em que o cotidiano do aluno adulto ingressa na sala de aula pela, digamos, "porta dos fundos". Problemas de trabalho, transporte, moradia, saúde e finanças são freqüentemente experimentados, na escola, como empecilhos ao processo de aprendizagem. Se o trabalho pedagógico deve pautar-se também pelo acervo de experiências dos alunos para construir saberes que lhes sejam significtaivos, uma muito tênue fronteira entre a cidade e a sala de aula acaba por investir o educador de atributos capazes de apoiar o enfrentamento de situações típicas do cotidiano na metrópole.

Essa dimensão da experiência pedagógica, possivelmente fruto da solidão e do desamparo do migrante, acaba por transferir à escola certas atribuições que fogem à sua alçada original.

3. No curso em questão, o trabalho dos educadores não se restringe aos confins das salas de aula. Em algumas ocasiões, realizamos saídas para espaços culturais da cidade como cinemas, teatros, parques e museus. Para alguns alunos, esses passeios representam uma primeira apresentação de lugares inéditos, cuja existência jamais fora concebida. Outras vezes, conduzem a recantos já visitados, muitas vezes com a própria escola, e que no entanto permaneceram fora de seus circuitos.

A privação desses espaços da cidade possui múltiplos determinantes. Passa pelo cotidiano todo preenchido pelo trabalho. Passa pela solidão que desencoraja a exploração do entorno e atrofia sua aproximação de uma cultura que então se mantém distante. Passa pelo imaginário de uma cidade impenetrável, fundado sobre estereótipos mas também sobre experiências concretas de inacessibilidade devida à falta de recursos financeiros. Finalmente, a privação de acesso ao espaço público decorre do iletramento que impede a informação. Esse conjunto de fatores, aliado ao 
prazer manifesto por quem aprende que a cidade conserva aberturas, levou a escola a ultrapassar seus limites físicos e fazer da cidade um objeto de parte de seus propósitos pedagógicos. Independente das relações que possam existir entre os passeios e os conteúdos estudados nas salas de aula, as saídas para a cidade ensinam a ir, quando ir e como ir.

Colocando em outros termos a tríade de aspectos acima apresentada, diria que minha convivência com migrantes vem gerando abalos que, nos termos de Gilberto Velho (1997), chamaria de estranhamento do familiar.

A presença de migrantes pertencentes às classes pobres é parte do cenário de uma cidade como São Paulo. À medida que sempre os encontrei, minha experiência como educador não equivaleu ao desvelamento de uma realidade impensada. Proporcionou, isto sim, a apreensão de alguns princípios e valores, motivos e interesses até então ignorados. Fez ver que o familiar pode ser desconhecido.

Essa experiência de estranhamento não se manteve restrita a uma nova perspectiva assumida sobre o viver e o pensar do grupo social de que fazem parte esses alunos. Mas culminou com novos pontos de vista desde os quais eu mesmo passei a estranhar instâncias sociais até então assimiladas e tomadas como arcabouço natural da existência.

Uma vida transcorrida toda ela em uma mesma cidade sofre as ameaças da conversão do familiar em uma realidade não mais percebida. A visão acostumada deixa de ser interceptada pela paisagem e pelas pessoas nela dispostas, restando ao corpo a reprodução de mecanismos motores habituais, já articulados às imagens dos objetos exteriores. A familiaridade arrisca tornar inexorável o olhar. Os sentidos dos acontecimentos cotidianos assumem caráteres definitivos, apresentados e reapresentados à consciência em formas consolidadas a priori, a despeito das experiências (Bosi, 2003).

O desequilíbrio causado pela escuta das narrativas de meus alunos sobre a cidade conferiu-me um olhar que muitas vezes é aquele de quem volta de uma viagem. Nessas ocasiões, o mergulho em universos materiais e simbólicos distantes gera um distanciamento dos modos de vida e de entendimentos do mundo com os quais estamos habituados. Muitas vezes, essa apreensão não se limita à duração cronológica da jornada, mas persiste conosco por um tempo mais. O cruzamento de fronteiras como que é capaz de conferir ao viajante o mesmo que uma mirada ao infinito proporciona à vista cansada: faz recobrar a capacidade de focar nuances onde apenas via borrões. $\mathrm{E}$ assim uma viagem se desdobra em um estranhamento do próprio mundo e de si mesmo.

Minha experiência como educador guarda afinidades com aquela que, para Lévi-Strauss (2004), é a do etnógrafo: um homem que, tocado pelo outro, jamais tornará a sentir-se em casa onde quer que venha a estar. Uma realidade até então tomada como dada e necessária passa a ser vista como uma entre outras tantas possibilidades.

Também o contato prolongado de um homem sedentário com o migrante é capaz de conduzi-lo a uma outra cidade que existe na sua e a leituras que ressignificam o mundo mais trivial. $\mathrm{O}$ apoio do outro permite ao nativo transcender a si mesmo, remetendo a um outro homem que pode habitar sua subjetividade. Já não há como sentir-se em casa dentro de si mesmo.

\section{EDUCAÇÃ0 E ACULTURAÇÃo}

\section{DeBiaggi (2005) define a} aculturação psicológica como um processo de ressocialização motivado por mudanças de contexto cultural e que assume variantes. Trata-se de um fenômeno característico de sociedades plurais, por isso relevante para a compreensão de formas de subjetivação em um mundo em que a circulação de pessoas é uma das dimensões mediante às quais têm sido ampliadas as arestas de contato entre formações outrora distantes.

Se o processo de aculturação vem sendo pensado à luz de experiências de migrantes e retornados - enfim, pessoas que transitam pelo globo, deixam para trás um tecido de socialização para viver em outro - é preciso considerar em que medida um traço específico desse fenômeno pode ser experimentado por um autóctone em longa convivência com grupos de migrantes.

Diferente daquele que se deslocou, o nativo é alguém que participa de um grupo majoritário. Seu contato com homens e mulheres relativamente a quem experimenta diferenças culturais não é concomitante à perda de seu vínculo com instituições e grupos sociais. Nesse sentido, sua aproximação de um outro contexto cultural assume um caráter reversível, pois o nativo ainda dispõe de alguma segurança oferecida pelas tramas sociais das quais participara até então. O que sua vivência conserva dos processos de aculturação é a incorporação de visões de mundo importadas de grupos de pessoas que 
transpõem seus contextos culturais para um universo distinto.

Uma reflexão sobre os traços de aculturação sofridos por um nativo que é professor de migrantes pertencentes às classes pobres não pode dispensar a problematização dos matizes assumidos pelo mesmo processo em seus alunos. Pois duas modalidades de cultura não se justapõem sem que a tensão de sua dialética dispare transformações em ambas as partes. As aculturações que estão em jogo em minha relação com os alunos merecem ser pensadas no seio das formas de relacionamento entre a cultura erudita e a cultura popular.

Ocupada com o tema da divulgação da cultura erudita ao povo, Ecléa Bosi (2003) aponta correntes da cultura acadêmica para as quais a incorporação das massas à civilização exigiria uma adoção passiva dos padrões oferecidos. Em uma escola para adultos que estivesse alinhada a esse pensamento, a aprendizagem formal exigiria uma ruptura com as formações mais precoces do aluno e sua assimilação por uma cultura dominante. Um professor apegado à sua cultura original, que lançasse mão de estratégias para manter-se distante da cultura do outro, mais reproduziria aqueles quadros em que o erudito simplesmente ignora as manifestações da cultura popular.

Em um pólo oposto estaria uma escola imobilizada pelo encantamento com a cultura popular. O que então se repetiria seriam os feitos das tendências de divulgação da cultura que proferem uma exaltação das manifestações do povo brasileiro, convertendo-as em objeto exótico e depositando em sua sabedoria a esperança de salvação da humanidade. Uma escola pautada por essa visão romântica também arriscaria precipitar sua prática em atitudes demagógico-populistas. A simpatia que pudesse haver pelo povo então se travestiria de uma comunidade falseada.

É importante esclarecer que esses modelos extremos possuem o valor de categorias teóricas, pois impeditivas de um projeto pedagógico efetivo. Por vias opostas, trazem subjacente uma concepção de educação que implica em um apagamento das diferenças e a construção de um campo de leituras uniformes do mundo.

Quando Simone Weil (1996) definiu o conceito psicossocial do enraizamento, preveniu-se contra leituras redutoras que pudessem pressupor o fenômeno como um isolamento da produção cultural de uma coletividade. Para a filósofa, as trocas de influências e a multiplicação de contatos podem fortalecer as raízes se o encontro com outras produções propicia aos homens envolvidos a mútua revelação da originalidade dos grupos de que participam.

Em um cenário em que a separação entre cultura erudita e cultura popular está relacionada às desigualdades da sociedade de classes, o esboço de alguma simetria exige um lugar para os saberes decorrentes das experiências concretas do povo. Uma articulação nesses termos não se faz plausível sem que os protagonistas da cultura dominante se ofereçam à perturbação inerente à revelação da condição humana de um outro que é mais outro.

Essa capacidade de habitação na perspectiva do diverso não decorre de um esforço voluntário, posto em prática em nome de uma causa externa que pudesse compensar calçar no dizer de alguns dos meus alunos - a ausência de uma comunidade de destino. Em meio a adultos pobres, migrantes em sua maioria, vivo eu mesmo a recorrente experiência de não ser compreendido e não compreender aqueles que estão à minha volta. A morada nesse território limítrofe ao qual pertenço e não pertenço confere a mim uma prova da experiência que, afinal, é a do próprio migrante. Então, a sala de aula de uma escola paulistana se converte em um terreno no qual podemos todos compartilhar a condição de estrangeiros neste mundo. Ele então se torna comum.

\section{* Fernando Frochtengarten é Mestre e Doutorando em Psicologia Social pela USP.}

\section{REFERÊNCIAS BIBLIOGRÁFICAS}

\section{BOSI, A.}

(2000) Cultura brasileira e culturas brasileiras. Dialética da colonização. São Paulo, Companhia das Letras, pp. 308-345.

BOSI, E.

(2003) Tempo vivo da memória. São Paulo, Ateliê.

DEBIAGGI, S. D.

(2005) "Migraçāo e implicações psicológicas: vivências reais para o individuo e o grupo". Travessia - Revista do Migrante, $n^{\circ} 53$, setembro-dezembro, pp. 16-20.

DURHAN, E. R.

(1973) A caminho da cidade: a vida rural e a migração para São Paulo. São Paulo, Perspectiva.

LÉVI-STRAUSS, C.

(2004) Tristes Trópicos. São Paulo, Companhia das Letras.

RIGOTTI, J. I. R.

(2006) "Geografia dos fluxos populacionais segundo niveis de escolaridade dos migrantes". Estudos Avançados, vol. 20, $n^{\circ} 57$, maio-agosto, pp. 237-254.

VELHO, G.

(1997) Observando o familiar. Individualismo e cultura. Rio de Janeiro, Jorge Zahar, pp. 121-132.

WEIL, S.

(1996) A condição operária e outros estudos sobre a opressão. Antologia 